\title{
Prensa, Religión y Revolución: discursos y representaciones de la Iglesia Católica Nicaragüense en la prensa costarricense, 1981- 1985
}

\author{
Press, Religion and Revolution: discourses and Representations of the \\ Nicaraguan Catholic Church in the Costa Rican Press, 1981-1985
}

Leonardo AsTORGA SÁNCHEZ

Universidad de Costa Rica

\begin{abstract}
RESUMEN
El artículo tiene como objetivo analizar cómo el discurso de la prensa costarricense, específicamente el periódico La Nación, el semanario Universidad y Libertad y el semanario el Eco Católico se encargaron de (re)presentar y discutir el papel de la Iglesia nicaragüense durante la década de 1980, en un contexto de Guerra Fría y en medio de la guerra contrarrevolucionaria. Se plantea que la discusión de la prensa en torno a la Iglesia se ubica como parte de una batalla política e ideológica sobre el rumbo seguido por la revolución, el tipo de democracia que se promovía y las concepciones que se poseían sobre Iglesia Popular, Justicia y Religión, entre otros.
\end{abstract}

PALABRAS CLAVE

Prensa; discurso; Iglesia; Nicaragua; Teología de la Liberación; Guerra Fría.

\begin{abstract}
The paper aims to analyse how the discourse of the Costa Rican press, specifically the newspaper La Nación and the weeklies Universidad, Libertad and Eco Católico, were responsible for (re) presenting and discussing the role of the Nicaraguan Church during the 1980, within a Cold War context and in the midst of the counterrevolutionary war. It is argued that the press's discussion of the Church should be located as part of the political and ideological battle over the course the revolution was to follow, the type of democracy to be promoted and the ideas held about the popular Church, justice and religion, among others.
\end{abstract}

\section{KEYWORDS}

Press; discourse; Church; Nicaragua; Liberation Theology; Cold War. 
El triunfo revolucionario del Frente Sandinista de Liberación Nacional (FSLN) en 1979, año en el que luego de una cruenta lucha la dinastía de la familia Somoza fue depuesta tras 30 años en el poder, posicionó a la organización guerrillera que había nacido en la clandestinidad como el principal actor político en Nicaragua. Esa posición privilegiada favoreció un proceso de hegemonización del proyecto revolucionario por parte del Frente.

Es ante esa posición de poder que, debido a la debilidad de la oposición política interna y la criticada y cuestionada participación de las fuerzas armadas contrarrevolucionarias en la lucha contra el sandinismo, la Iglesia Católica nicaragüense pasó a representar la cara legítima del antisandinismo. Es por tal razón que el presente artículo se propone analizar cómo desde cuatro diarios costarricenses se llegó a construir y (re)presentar a la Iglesia durante el conflicto armado en Nicaragua.

Con el objetivo de vislumbrar la manera en que desde el discurso mediático de la prensa se construyó una idea de Iglesia, resulta necesario entender, según la visión de los periódicos, la labor que la religión y la institución cumplían. A su vez, cómo ese imaginario se relacionaba, en las páginas de los rotativos, con qué tipo de democracia se debía promover y qué valores eran los que debían definir el rumbo del proyecto revolucionario.

Sobre los periódicos escogidos se debe mencionar que uno de ellos, La Nación, tradicionalmente (desde su fundación en 1945) se ha identificado con los sectores más conservadores de la sociedad costarricense ${ }^{1}$, y ha sido tribuna para que una derecha de corte liberal se exprese y exponga sus ideas, cuyo mensaje se ha caracterizado por un fuerte tinte anticomunista ${ }^{2}$. Igualmente, el diario, durante la década de 1980 y en el marco de la crisis centroamericana, tomaría una postura muy cercana a la política exterior de la administración Reagan, apoyando una posición beligerante hacia Nicaragua.

De los otros tres periódicos, los cuales a diferencia de La Nación tenían un carácter semanal (siendo por lo tantos semanarios), debemos mencionar que Libertad era el órgano de prensa del Partido Vanguardia Popular, principal organización de izquierda de Costa Rica, cuya historia data de la década de 1930. Este semanario estuvo bajo la dirección de Eduardo Mora, hermano de Manuel Mora, líder histórico del comunismo costarricense ${ }^{3}$.

Sobre Universidad se puede rescatar el carácter de prensa institucional, siendo un medio vinculado con la principal casa de estudios de Costa Rica, la Universidad de Costa Rica. El semanario vio su nacimiento en 1970 y desde ese momento pasó a ser el espacio para que miembros de la comunidad académica y cultural costarricense, especialmente profesores, expresaran sus opiniones y reflexiones en torno a temas políticos, económicos y culturales. Tanto Libertad como Universidad tomaron una postura abiertamente favorable hacia el proceso revolucionario que se estaba llevando a cabo en Nicaragua, defendiendo el derecho a la autodeterminación de los pueblos y criticando la política de Estados Unidos hacia Centroamérica.

1. Francisco RiverA y Koen Voorend, "Los duelos de la palabra en Costa Rica en un contexto de reforma neoliberal,” Revista Rupturas, vol. 1, n. 2, 2012, pp. 144-161.

2. Willy Sото, Ideología y medios de comunicación. Fetichismo, manipulación y guerra psicológica, San José de Costa Rica, Alma Mater, 1987.

3. Sofía CORTÉs, ¿Comunismo a la tica o comunismo soviético? La división del partido Vanguardia Popular en Costa Rica (1983-1984), San José, Centro de Investigaciones Históricas de América Central, 2020. 
El cuarto semanario sería el Eco Católico, que hizo su aparición en mayo de 1931, llegando a ser, debido a su longevidad, un éxito para la Iglesia Católica costarricense ${ }^{4}$. Sobre este semanario se debe destacar que para la década de 1980, de la mano de su director el presbítero y también periodista Armando Alfaro, optó por una posición que buscó colocar a la Iglesia como rectora, ejemplo y consejera ante las dificultades que enfrentaba la región. Lo anterior permitía que desde sus páginas, y apelando a una autoridad moral, se lanzaran críticas en contra de los regímenes con una orientación izquierdista, pero también en contra de aquellos que hacían un llamado a la intervención norteamericana y una salida militar al conflicto.

Habiendo hecho una presentación de cuáles serán las fuentes que nutran al artículo, es pertinente mencionar que se trabajará con la línea editorial y de opinión, esperando así poder identificar en el discurso sobre la Iglesia nicaragüense los elementos que dan forma al discurso y a las representaciones sobre la misma. Asimismo, se señalará la importancia de aquellos que escribían en las páginas de los periódicos y su papel como líderes de opinión, poseedores de un capital social y simbólico, siendo éste un resultado directo de pertenecer a un medio (la prensa) que los acreditaba o les brindaba un espacio para expresarse.

De tal manera, el artículo parte de considerar a la prensa como una entidad o espacio de socialización que cuenta con sus propios intereses y crea normas y valores acordes a su posición política e ideológica ${ }^{5}$, y con ello el discurso mediático pasa a ser un fenómeno, una práctica social determinante en el proceso de construcción y representación de la realidad. De ahí la importancia de quienes colaboraban y trabajan con los respectivos medios y su papel, como lo reconoce Jürgen Habermas, de líderes generadores de opinión, con un capital simbólico que responde a las normas y valores, los marcos de referencia, de la institución mediática ${ }^{6}$. Por tanto, el discurso mediático, a través de sus colaboradores y periodistas (líderes de opinión) se convierte en un productor de sentido, una fuente desde la cual las personas obtienen no solo información, también conforman opiniones, y todo esto dentro del parámetro establecido por la cultura institucional del medio, la cual, a su vez, debe ser ubicada en un contexto, un momento histórico que la va a definir e influenciar.

\section{Monseñor Obando y Bravo y la Iglesia Católica (tradicional)}

Durante los años que vivió en Nicaragua, el periodista Stephen Kinzer señaló cómo su pueblo se caracterizaba por un fuerte sentimiento religioso ${ }^{7}$, sentimiento que se apoyaba en una relación muy cercana entre los nicaragüenses y los sacerdotes de la Iglesia Católica. Esa relación casi paternal, durante la década de 1980, derivó en una fuerte polarización social, que tuvo como motivo el enfrentamiento entre el proyecto revolucionario del Frente y la Iglesia. Como lo señala Salvador Martí, el proyecto

4. Eugenio RIVERA, "La circulación de la prensa católica costarricense en los años 30. Un análisis de Eco Católico”, Cuadernos Inter.c.ambio sobre Centroamérica y el Caribe, vol. 18, n. 1 (2021).

5. Bárbara TORO, “Medios masivos de comunicación: una construcción de la realidad”, Revista Pequén, vol.1, n. 1 (2011), p. 109.

6. Jürgen HaBermas, Historia y crítica de la opinión pública, México, G. Gili, 1986, p. 227.

7. Stephen KInZER, Blood of brothers, Cambridge, David Rockefeller Center for Latin American Studies, 2007, p. 191. 
sandinista se ganó la hostilidad de la jerarquía de la Iglesia, y por ende de buena parte de la población, que asumía como propios los valores tradicionales religiosos ${ }^{8}$.

Fue así como diferentes sucesos, entre ellos una supuesta aparición de la Virgen María en un pueblo en el interior de Nicaragua, pasaron a ser motivos de discusión y enfrentamiento político. Mientras que los sandinistas restaban importancia al evento, la oposición anti sandinista (con la Iglesia a la cabeza) consideró que la aparición de la Virgen era un mensaje político dirigido en contra del régimen del FSLN ${ }^{9}$.

El conflicto entre la Iglesia Católica y el Frente ocupó un lugar central durante la década de 1980. Fue una pugna tanto política como ideológica (con elementos religiosos propios de una lucha entre el bien y el mal), cuyos momentos más culminantes se insertaron en una lógica de acción/reacción entre ambos bandos, en constantes ataques y denuncias, por un lado la Iglesia y Monseñor Obando y Bravo, denunciando el rumbo que tomaba la Revolución (el llamado giro a la izquierda); y por otro, el FSLN, preocupado por consolidar y fortalecer el poder, antes que dialogar y establecer una adecuada política de relaciones con la Iglesia ${ }^{10}$.

Durante los años en los que el sandinismo se mantuvo en el poder (1979-1990), la Iglesia Católica fue, si no la principal, una de las instituciones opositoras más importantes al régimen; ese papel se ratificó luego de las elecciones de 1984, ante la incapacidad de la oposición política anti sandinista ${ }^{11}$. El proceso de consolidación y legitimación del Gobierno, posterior a las elecciones de 1984, fue testigo también de un constante debilitamiento de los oponentes políticos del Frente. Por tal razón, la única institución no sandinista que permanecía intacta, inclusive más fuerte y poderosa, era la Iglesia Católica, que valiéndose de la popularidad entre la población logró hacer de Obando y Bravo y la Conferencia Episcopal Nicaragüense (CEN), los líderes anti sandinistas más destacados al interior de Nicaragua (y con una importante cuota de legitimidad en el exterior). Ellos tenían los recursos, la autoridad moral y la base institucional que el resto de la oposición no poseía ${ }^{12}$.

De tal manera, la Iglesia Católica (tradicional) como institución llegó a poseer una capacidad enorme de movilización popular, que le disputaba al Frente uno de los elementos claves para la consolidación (y el éxito) de cualquier proyecto político (e ideológico), el control sobre el pueblo y su manera de entender y vivir el mundo, la creación de sentido común a partir de una visión particular de la realidad. Es así que, aprovechando la importante cuota de apoyo, ligada a una experiencia religiosa compartida por los nicaragüenses (en su mayoría), la Iglesia, con Obando y Bravo a la cabeza, hizo posible que la oposición al sandinismo al interior de Nicaragua se legitimara.

Unido a lo expuesto arriba se puede agregar que, en un país como Nicaragua, en donde no se desarrolló un sistema fuerte de partidos u otros centros de pensamiento independiente al poder del Gobierno, la Iglesia jugaba un papel importante en la dinámica política y social del país. Se debe aclarar que, en un principio, durante la insurrección

8. Salvador MARTí, La revolución enredada, Barcelona, Libros de la Catarata, 1997, pp.104.

9. KINZER, Blood of brothers, p. 192.

10. Guillermo MELÉNDEZ, Otro mundo y otra iglesia son posibles: un acercamiento al catolicismo centroamericano contemporáneo, San José, DEI, 2008, pp. 181-182.

11. Oscar VARGAS, El sandinismo: 20 años después, Managua, Centro Nicaragüense de Escritores, 1999, p. 127.

12. KINZER, Blood of brothers, p. 193. 
final y los primeros meses de Gobierno sandinista, las relaciones entre la Iglesia y el Frente fueron cordiales: la Conferencia Episcopal Nicaragüense (CEN) en junio de 1979, emitió una carta pastoral justificando la insurrección y al mes siguiente otra saludando el triunfo sandinista, mientras que en 1980 los comandantes reconocían el papel desempeñado por Obando y Bravo en la lucha contra Somoza ${ }^{13}$.

Sin embargo, rápidamente, a finales de 1980, la cordialidad entre Iglesia y Gobierno empezó a desaparecer, dando paso al enfrentamiento. La salida de Alfonso Robelo y Violeta Barrios de la Junta de Gobierno de Reconstrucción Nacional (mayo de 1980) y la presencia de sacerdotes en puestos de gobierno ${ }^{14}$ fueron elementos que la Iglesia criticó abiertamente, catalogándolos como muestras innegables de las tendencias hegemonizantes del régimen. A lo anterior hay que agregar la defensa que la institución hacía de un espacio de influencia espiritual (que a la vez era político) que el Frente disputaba con mayor fuerza (con el sandinismo como nueva cultura nacional e ideología).

En 1982, la situación no tuvo vuelta atrás y la brecha se terminó de abrir y ampliar cuando la Dirección General de Seguridad del Estado (adscrita al Ministerio del Interior) tramó y trató de involucrar en un escándalo sexual al padre Bismarck Carballo, mano derecha de Obando y Bravo ${ }^{15}$. A partir de esa ruptura, La Nación aprovechó el conflicto y la cuestión religiosa no solo para deslegitimar al FSLN, sino también para presentar a los sandinistas como personajes ajenos al ser nicaragüense, incluso negándoles su pertenencia a la nación, al presentarlos como comunistas ateos, algo totalmente opuesto a un pueblo en donde casi el 80 por ciento (durante la década de 1980) de la población era católica, muy tradicional y leal a Obando y Bravo ${ }^{16}$.

La Nación, desde sus editoriales, fustigó al régimen y acusó que el proceso revolucionario no era más que un burdo adoctrinamiento de la población; más importante aún, el discurso señalaba que ante esos planes se oponía la Iglesia, y por tal razón ésta era perseguida. Esa persecución, que para el diario tenía como fin la destrucción de la Iglesia, fue presentada como una muestra innegable del carácter antidemocrático y ateo (elementos que van de la mano) de toda revolución de corte, o tendencia, marxista, y así lo expresaba un editorial del 11 de julio de 1984:

El cuadro de la revolución bolchevique de 1917 y, después de la Segunda Guerra Mundial, de todos los países que fueron cayendo bajo el dominio del imperialismo soviético, es el mismo respecto a la Iglesia y la religión en general. El choque, por esta misma razón, entre el régimen totalitario de Managua, a pesar de que esta fue uno de los aliados más decididos y decisivos de la insurrección contra de la dictadura de Somoza, estaba inexorablemente inscrito ya en los planes de transformación revolucionaria de Nicaragua a un modelo marxista leninista como el de Cuba. De la misma manera que en Cuba y en el resto de mundo comunista se ha aniquilado a la Iglesia y a la religión con las armas, sin contemplaciones, reduciéndolas a su mínima y más discreta representación, en la Nicaragua de hoy, como corresponde a un régimen totalitario, se está en esa faena de opresión abierta y erradicación brutal de las creencias del pueblo ${ }^{17}$.

13. Ibídem, pp. 195-196.

14. Los sacerdotes en puestos de gobierno eran: Fernando Cardenal, como Ministro de Educación; Ernesto Cardenal, Ministro de Cultura; Edgar Parrales, Ministro de Bienestar Social y luego embajador de Nicaragua ante la OEA, y Miguel D’Escoto, Ministro de Relaciones Exteriores.

15. KINZER, Blood of brothers, p. 199.

16. Ibídem, p. 200.

17. “La persecución de la Iglesia”, La Nación, 11-7-1984, p. 14A. 
Otro editorial, esta vez del 6 de abril de 1982, denunciaba cómo entre las muchas violaciones a los Derechos Humanos se podía contar la represión de la fe, lo cual era una afrenta no solo al pueblo nicaragüense, también a Dios. Tal discurso permitía presentar al Gobierno del FSLN como ilegitimo, tanto por violar los preceptos democráticos y el mandato divino, atentando contra las bases que según Occidente definían el buen funcionamiento de la sociedad (democracia y religión):

Para los comandantes la religión sigue siendo “el opio del pueblo” y la Iglesia un instrumento de alienación al servicio de la burguesía capitalista. De ahí que, aprovechando el clima político creado por el peligro de una supuesta invasión, el gobierno sandinista haya declarado los días santos como obligatoriamente laborales.

De lo que se trata es de ir socavando la tradición religiosa de las procesiones y del culto a la memoria de la pasión evangélica. Con estas disposiciones se impide a las masas populares asistir a los oficios religiosos so pretexto de una emergencia imaginaria. La religiosidad de los nicaragüenses es para los sandinistas un gran obstáculo en el proceso de aceleración sovietizante en que están embarcados ${ }^{18}$.

Lo expuesto por los editoriales citados era complementado por quienes escribían en el diario; así lo dejaba ver quien fuera jefe de información y luego sub director Juan Sánchez, en la columna del 7 de abril de 1982, al considerar como un "extravío mental [...] la medida de cercenar los sentimientos religiosos de un pueblo católico como lo es el nicaragüense” ${ }^{19}$. Igualmente, el columnista y abogado Enrique Benavides explicaba el 19 de agosto de 1982 que en un régimen de orientación marxista como el nicaragüense,

uno de los rasgos más sobresalientes [...] es la persecución religiosa, esto es, la campaña para desestabilizar y desprestigiar a la Iglesia [...] los comandantes, bajo la batuta cubana, han echado a andar una campaña de penetración y destrucción de las creencias religiosas

114 que en los nicaragüenses están particularmente arraigadas $^{20}$.

El discurso de La Nación y sus colaboradores se encargó, por lo tanto, de presentar a los sandinistas como los únicos capaces de desestabilizar y desprestigiar, hacer ver a la Iglesia como una víctima indefensa ante la maquinaria de un Estado totalitario. No obstante, no se reconocía que la Iglesia, durante los años que duró el conflicto con el Gobierno, fue la portavoz de los sectores más conservadores de la sociedad nicaragüense, muchos de ellos simpatizantes de la dictadura somocista o temerosos del proceso revolucionario ${ }^{21}$, y que sus denuncias nunca fueron imparciales, ya que mientras acusaba a los sandinistas de violar los Derechos Humanos y persecución religiosa, no hacía lo mismo con las atrocidades cometidas por la Contra, ignorando y hasta legitimando sus abusos $^{22}$.

La Nación, mediante su discurso, mostró la persecución religiosa como una consecuencia directa de la personalidad de los sandinistas. Esa relación entre persecución y personalidad, permitió al periódico caracterizarlos como monstruos, o en términos religiosos, como demonios. Autores como David Díaz han analizado cómo el discurso anticomunista, en momentos de fuerte conflictividad social, se valió de la monstrificación

18. “En Nicaragua, fe reprimida”, La Nación, 6-4-1982, p. 14A.

19. Juan SÁNCHEZ, “La columna”, La Nación, 7-4-1982, p. 15A.

20. Enrique BENAVIDES, “La columna”, La Nación, 19-8-1982, p. 15A.

21. MELÉnDEZ, Otro mundo y otra Iglesia son posibles, p. 182.

22. KINZER, Blood of brothers, p. 207.

Rubrica Contemporanea, vol. X, n. 20, 2021 
de sus adversarios para normalizar y legitimar acciones en su contra que, en otro contexto, serían vistas como cuestionables o reprobables ${ }^{23}$

Al demonizar a los sandinistas (no solo eran ateos) se establecía una distancia con el resto del pueblo, distancia que, como señala Jonathan Glover, les privaba de su humanidad, neutralizando o anulando los principios morales que evitan acciones violentas (la violencia discursiva genera también en violencia física) en su contra ${ }^{24}$. Hay una completa pérdida de simpatía (o empatía) que reduce el sentimiento de responsabilidad emocional, se vive bajo una psicología de guerra ${ }^{25}$, a lo que se le debe sumar el anticomunismo que Edelberto Torres-Rivas define como una mentalidad, una forma de pensar y una práctica política y simbólica basada en los prejuicios y creadora de estereotipos, y que apelaba más a lo emotivo que a lo racional ${ }^{26}$.

Esa psicología de guerra encontraba en las publicaciones de La Nación una de sus mayores expresiones. Para Juan Sánchez, el 1 de noviembre de 1983, en la sección "Buenos días”, el carácter monstruoso de los sandinistas quedaba en evidencia cuando:

atacan a los obispos y templos que fueron sus escudos durante la insurrección. Atacan a la libertad de credo que junto con la de prensa constituyen las madres de todas las otras libertades. No pueden contemplar impávidos que el pueblo rinda culto al Señor, cuando en sus desquiciadas cabezas debía hacerlo a los comandantes ${ }^{27}$.

El periodista Rogelio Benavides, el 24 de junio de 1984, en la sección “Opinión del Redactor,” denunciaba cómo:

queriendo encontrar a un responsable de los graves problemas que sufre el país, el FSLN ha emprendido una amplia persecución contra la Iglesia católica nicaragüense. [Los sandinistas] tratan de aniquilar la fe de un pueblo que ya no cree en el proyecto "revolucionario" ni en los nueve comandantes que han usurpado el $\operatorname{poder}^{28}$.

Frente a esos demonios, La Nación posicionaba la Iglesia como uno de los principales baluartes en su lucha contra el comunismo. Víctor Hugo Murillo, también periodista del diario, en un artículo del 15 de julio de 1984, señalaba que la Iglesia era poseedora de una importante autoridad moral para criticar al régimen: "el enfrentamiento entre ambos sectores comienza a producirse justamente cuando las autoridades eclesiásticas hacen cuestionamientos a la autoridad gubernamental. Esto genera una irritación al sandinismo, que ha demostrado una total incapacidad e inmadurez para soportar la crítica”29. Igualmente, Enrique Benavides, el 18 de noviembre de 1983, destacaba cómo "la Iglesia sobresale con un mensaje de tolerancia, de respeto a la condición humana, de reivindicación de la libertad”30.

23. David DíAz, Crisis social y memorias en lucha: guerra civil en Costa Rica, 1940-1948, San José, Editorial de la UCR, 2015, p. 258.

24. Jonathan GLOVER, Humanidad e inhumanidad. Una historia moral del siglo XX, Madrid, Cátedra, 2011, pp. 78-79.

25. Ibídem, p. 74.

26. Edelberto TORRES-RIVAs, Revoluciones sin cambios revolucionarios. Ensayos sobre la crisis en Centroamérica, Guatemala, F\&G Editores, 2013, pp. 234-236.

27. “El lumpen del terror”, La Nación, 1-11-1983, p. 14A.

28. “Siempre la Iglesia”, La Nación, 24-6-1984, p. 15A.

29. “De nuevo ante una torpeza”, La Nación, 15 de julio de 1984, p. 15A.

30. “La columna”, La Nación, 8-11-1983, p. 15A.

Rubrica Contemporanea, vol. X, n. 20, 2021 
La autoridad moral y las características (positivas) que señalaba Benavides, oponiéndolas a la intransigencia y el dogmatismo comunista, se complementan con una vocación de lucha milenaria que, según los redactores, ha caracterizado a la institución desde sus inicios. Así lo exponía otro de los colaboradores del diario Eduardo Castro, en “Opinión del Redactor," del 6 de marzo de 1983: "el pueblo nicaragüense es un auténticamente creyente, cristiano, luchador, que no permitirá más ser rebaño de humillados y ofendidos. Los nueve detentadores del poder han fortalecido el espíritu de pelea de la Iglesia, indómito por dos mil años”31.

Un lugar destacado dentro de las publicaciones de La Nación lo tuvo Monseñor Obando y Bravo, quien pasó a ser presentado como un buen pastor y mártir, que se sacrificaba por el pueblo. El 12 de julio de 1982, en un editorial sobre Obando y Bravo se publicaba lo siguiente:

\begin{abstract}
La sombría dictadura de los comandantes, que no del proletariado, estrecha cada vez más un cerco de vigilancia contra el Arzobispo de Managua, Monseñor Obando y Bravo. El propósito de esta virtual privación de la libertad es sacarlo del país tan pronto como se le pueda comprobar una palabra contra el régimen que pueda ser calificada por el gobierno de traición o contrarrevolución.

Una expulsión de Monseñor Obando y Bravo, el valiente prelado que con tanto coraje y decisión peleó desde su púlpito contra el otro despotismo y llegó hasta admitir la posibilidad en Nicaragua de un socialismo en libertad, será la culminación política de la desaforada ambición de los comandantes por cerrar de una vez por todas cualquier posibilidad de ser tumbados del poder ${ }^{32}$.
\end{abstract}

En la sección "Foro," (dedicada a ser el espacio en el que publicaban y escribían miembros de la derecha liberal costarricense), del 14 de marzo de 1983, el ingeniero José Sauma describía cómo:

la cruz de Monseñor Obando y Bravo es una cruz pesada, pero llevada con valentía y aplomo: es un hombre valiente, un pastor admirable. Y la Iglesia en Nicaragua es una Iglesia mártir, perseguida, humillada y despreciada, en la persona del Arzobispo [...] que sufre acosado por una jauría minoritaria que perdió su condición humana ${ }^{33}$.

Mientras que, “Nicaragua Hoy”34, suplemento semanal publicado los sábados en La Nación y dirigido por la oposición anti sandinista exiliada en Costa Rica, destacaba de Obando y Bravo su origen campesino y humilde, que lo acercaba al pueblo, al ser "un pastor sacado de la montaña y del caminito comarcano donde solía andar a lomo de mula predicando el Evangelio a los campesinos”35. Y así como Obando y Bravo era el paradigma del buen pastor, los obispos y sacerdotes fieles a él compartían esa imagen, como lo aseveraba el escritor y columnista español radicado en Costa Rica Pablo Cejudo, luego de que el FSLN por razones de seguridad decidiera expulsar a diez sacerdotes extranjeros: "al considerar como personas no gratas en Nicaragua a estos diez apóstoles, el régimen sandinista demuestra que le resultan incómodos todos lo que no se acomoden a sus cálculos” ${ }^{36}$.

31. “Humillados y ofendidos”, La Nación, 6-3-1983, p. 14A.

32. “Obando y Bravo: un virtual prisionero”, La Nación, 12-7-1982, p. 14A.

33. “A buen entendedor”, La Nación, 14-3-1983, p. 16A.

34. El suplemento Nicaragua hoy, se publicaba en La Nación todos los sábados entre 1985 y 1990 . Este suplemento fue la voz de los opositores y disidentes antisandinistas exiliados en Costa Rica.

35. Nicaragua Hoy, 22-6-1985, p. 2C.

36. “Nicaragua: clérigos non gratos”, La Nación, 15-7-1984, p. 14A. 
El discurso de La Nación, se encargó de contrastar la mansedumbre, entrega y sacrificio de Obando y Bravo, los sacerdotes y el pueblo nicaragüense (al que no pertenecían los sandinistas) frente a la violencia y el salvajismo del sandinismo, cuya mejor expresión eran las llamadas Turbas Divinas, especie de grupo de choque integrado en su mayoría por jóvenes miembros de las organizaciones de masas, que como elemento no controlado por el FSLN (o reprimido) se encargaron de hostigar públicamente a quienes estaban en contra del proyecto revolucionario ${ }^{37}$. El 3 de noviembre de 1983, en un editorial, La Nación denunciaba como “[...] las llamadas 'turbas divinas' la emprenden contra los católicos que asisten a los templos en obediencia a un llamado de su fe" ${ }^{38}$, y Jorge Rossi (empresario, abogado y Vicepresidente de Costa Rica entre 1970 y 1974), en "Foro" del 10 de marzo de 1983, describía a las Turbas como "las que hace casi 2 mil años rechazaron la tímida y falaz sugerencia de Pilatos para liberar a Jesús y gritaron: A Barrabás, suéltanos a Barrabás... ¡A Cristo, crucifícalo... crucifícalo!”39. Finalmente, la profesora Leticia Chacón establecía la más clara diferencia entre las Turbas (los sandinistas) y los nicaragüenses, luego de una marcha (de 300 personas) en contra de la reclusión del sacerdote Luis Amado Peña, quien al parecer se había encargado de proveer de armas a los contrarrevolucionarios según informes del Ministerio del Interior.

Esas mujeres, niños y hombres no tuvieron temor a expresar su repudio y su rechazo a los desmanes del Gobierno sandinista contra la Iglesia Católica. No escondieron sus rostros. Marcharon cara al sol, con la mirada altiva, desafiando a las ‘turbas divinas’ que no saben de dignidad humana, ni de la justicia, ni del amor a Dios.

Y los hombres, mujeres y niños [...] ya están señalados uno a uno por las 'turbas divinas’ y por los esbirros del Gobierno sandinista. Serán nuevos mártires nicaragüenses en la persecución religiosa implacable del régimen marxista que pretende aplastar a una Iglesia eterna $^{40}$.

\section{Iglesia Popular y Teología de la Liberación}

Otro tema importante discutido en los periódicos fue el enfrentamiento entre la Iglesia Oficial y la Iglesia Popular, ésta última promovida y apoyada por el FSLN. Esas dos formas de entender la Iglesia y su misión en la Tierra permitieron a los periódicos apoyar o criticar el proyecto sandinista, como ya se había hecho con el tema de la democracia. Universidad y Libertad se posicionaron del lado de la Iglesia Popular, defendiendo a ésta como parte de los esfuerzos liberadores y emancipadores de la Revolución.

Hay que entender que la llamada Iglesia Popular fue una expresión más de lo que en Latinoamérica se llegó a conocer (y practicar) como la Teología de la Liberación, corriente teológica cristiana que luego de las reformas del Concilio Vaticano II (19621965) y las conferencias episcopales de Medellín (1968) y Puebla (1979) promovió una idea de Iglesia del lado de los pobres, una opción preferencial por ellos. Además de buscar su salvación espiritual, también abogaba por su salvación material (mejores condiciones de vida y respeto de su dignidad como personas), denunciando la pobreza, la violencia y la injusticia como pecados (o el Pecado Institucionalizado) causados por la opresión y

37. José Coraggio y Rosa Torres, Transición y crisis en Nicaragua, Quito, El Conejo, 1987, p. 64.

38. “La Iglesia en Nicaragua”, La Nación, 3-11-1983, p. 14A.

39. “El segundo viernes santo”, La Nación, 10-3-1983, p. 16A.

40. Leticia Chacón, “Que valientes”, La Nación, 15-7-1984, p. 16A.

Rubrica Contemporanea, vol. X, n. 20, 2021 
marginación a las que eran sometidos y vivían los pueblos latinoamericanos ${ }^{41}$. Desde la Teología de la Liberación se planteaba necesario concebir la historia como un proceso de liberación ${ }^{42}$, en donde los aspectos políticos, económicos y sociales eran tan importantes como lo espiritual. En tal proceso, la Iglesia debía jugar un papel fundamental y de fuerte crítica y acción ante las situaciones de injusticia y desigualdad causadas tanto por la situación de dependencia de la región como por los gobiernos y los sectores dominantes de cada país ${ }^{43}$.

La Iglesia como institución debía ser crítica y liberadora ${ }^{44}$, trabajar y actuar al lado de los pobres (actores activos en el proceso de liberación) y sus luchas. Tal ideal llevó a muchos sacerdotes, religiosas y laicos no solo a crear e integrar las Comunidades Eclesiales de Base ${ }^{45}$, sino también a pensar la fe desde una dimensión política, es decir, una toma de conciencia (y posición) ante la injusticia (el Pecado) ${ }^{46}$.

La dimensión política de la fe, la crítica a las políticas desarrollistas ${ }^{47}$ puestas en práctica en América Latina desde la década de 1950 (considerándolas como insuficientes, como paliativo de los sectores dominantes para evitar la conflictividad social y la politización de los más necesitados) ${ }^{48}$, y la idea que el verdadero desarrollo y la total liberación solo se lograban mediante una transformación radical de la sociedad (construir el reino de Dios en la Tierra, el acceso al poder de la clase explotada y marginada), acercaron a quienes profesaban la Teología de la Liberación a los grupos y organizaciones de izquierda, entre ellas el FSLN, que luchaban contra gobiernos dictatoriales y autoritarios. Además, la concepción (o el imperativo moral) que tenía la corriente teológica del buen cristiano, aquel que trataba de transformar las causas estructurales de la inequidad y la violencia ${ }^{49}$, y esa idea de transformación, se acomodaba muy bien con la idea de revolución (y del Hombre Nuevo) como una vía de traer justicia social a la Tierra.

Con la llegada al poder del FSLN, Nicaragua se convirtió en un laboratorio, un campo de experimentación para los teólogos de la liberación, que contaron con el apoyo de las autoridades del Frente, y estos vieron en la Iglesia Popular la oportunidad de dotar de mayor legitimidad el proyecto sandinista. Libertad y Universidad se encargaron, desde

41. Julio LOIS, Teología de la liberación: opción por los pobres, San José, DEI, 1988, p. 129.

42. Gustavo GutiÉRrez, Teología de la liberación. Perspectivas, Salamanca, Ediciones Sígueme, 1999, p. 91.

43. Ibídem, p. 67.

44. Ibídem, p. 265.

45. Las comunidades Eclesiales de Base (que surgieron de la experiencia brasileña en la década de 1960), fueron el núcleo de trabajo donde tanto laicos como religiosos se reunían para leer y comentar la Biblia, y también para realizar actividades orientadas a la discusión y la acción política y social, con una vinculación fuerte con los movimientos populares (ver Jorge CÁCERES y otros, Iglesia, política y profecía. Juan Pablo II en Centroamérica, San José, EDUCA, 1983, p. 79).

46. GUTIÉRREZ, Teología de la liberación, pp. 268.

47. En la Teología de la Liberación, desarrollismo no es lo mismo que desarrollo, ya que el primero ve todo en términos económicos y modernizantes, mientras que el segundo debe ser más integral, no solo lo económico debe estar presente, es necesario un enfoque humanista, que vea al ser humano como actor principal de la historia (Ibídem, pp. 76-77).

48. Ibídem, pp. 78-80 y 127-130.

49. Greg Grandin, Empire's Workshop: Latin America, the United States, and the Rise of the New Imperialism. Nueva York, Holt Paperbacks, 2007, p. 146. 
sus publicaciones, de defender a la Iglesia Popular y la máxima de que entre sandinismo (comunismo) y cristianismo no había contradicción, sino que se complementaban muy bien. El poeta y ensayista español Antidio Cabal, en un artículo publicado en Universidad, en la semana del 3 al 9 de febrero de 1984, explicaba cómo

\begin{abstract}
La llegada revolucionaria de los sandinistas al poder es también, por primera vez en la historia de las revoluciones socialistas, la llegada del cristianismo al poder, fundamentalmente en su dinámica católica.

[...] el pueblo nicaragüense se ha convertido en sujeto real de su religión, se ha apropiado de su fe y, en consecuencia, del hacer de su fe. Pero este mismo pueblo dueño de la concepción ortodoxa del Evangelio es el mismo pueblo dueño de la revolución sandinista y por ello unificador, en el campo de la historia, en la humanidad de base, de dos concepciones del mundo que en orden a la justicia y a la libertad imponen el mismo plan de trabajo, un solo modo de producir la verdad social [...] la revolución sandinista enriquece la tarea de la fe, la oportunidad es incalculable para que el cristianismo se cristianice $^{50}$.
\end{abstract}

El mismo artículo se encargaba de establecer la diferencia entre la Iglesia Popular y la Iglesia Oficial:

El modo de la verdad de los que tienen fe y hambre simultáneamente y el modo de la verdad de los que tienen fe y riquezas simultáneamente se enfrentan en Nicaragua, los jóvenes pobres y hambrientos en favor de la Iglesia y la revolución sandinista y los jóvenes ricos y hartos en contra de la revolución y por lo tanto contra la Iglesia. Si la Iglesia quiere constituirse al fin en la buena nueva, y no simplemente identificarse con la moral acomodaticia del joven rico del que habla el Evangelio, el modelo revolucionario nicaragüense le es imprescindible. No hay Iglesia sin pueblo ${ }^{51}$.

En otro artículo, publicado la semana del 10 al 16 de febrero de 1984, Cabal justificaba y defendía la presencia de sacerdotes en puestos de Gobierno. Así como en la prensa con una posición desfavorable hacia la Revolución el anti comunismo se podía catalogar como el elemento distintivo, en Universidad, la conciencia social y valores progresistas (nacionalismo, antiimperialismo, defensa o promoción de un Estado política, económica y socialmente comprometido) tomaban ese lugar, y caracterizaban a los sandinistas como los adalides del pueblo y las causas justas y comprometidas; y más importante aún, representantes de Dios en la tierra, al contribuir con la construcción de su reino:

Dios no está prohibido en Nicaragua. Por lo contrario, Dios es cogobernante en Nicaragua. Para qué mentir. A su cargo están las relaciones internacionales de la revolución; dirige, impulsa y tiene bajo su responsabilidad la cantidad, la calidad y la expansión del espíritu cultural del pueblo de Nicaragua [...] orienta la organización de la juventud y la heroica estructuración humana de la alfabetización; en la Organización de Estados Americanos (OEA), representa a Nicaragua ante todos los países de América. Cada una de estas cuatro decisivas dimensiones del gobierno sandinista (y hay más) está dirigida por un sacerdote. En Nicaragua el sandinismo respeta hasta la libertad de religión que rinde culto al Dios rockefeleriano que los contrarrevolucionarios quieren hacer pasar por cristianismo. O sea, que la revolución respeta el culto a un ídolo de naturaleza capitalista $^{52}$.

En Libertad, sería la escritora, actriz y directora teatral Virginia Grutter (cuyo pasado militante la caracterizaba), en la sección “Señales,” del 13 al 19 de julio de 1984, quien se encargaría de caracterizar a la Iglesia oficial, a Obando y Bravo y la CEN, como

50. “Nicaragua y cristianismo”, Universidad, n. 616, 2-1984, n. 616, p. 5.

51. Ibídem.

52. “El obispo de Bluefields”, Universidad, n. 617, 2-1984, p. 6. 
un grupo de oportunistas y reaccionarios y, al igual que lo hacía La Nación, se estableció una diferencia y distancia entre la Iglesia oficial y el pueblo nicaragüense. Para Grutter, la Iglesia de Obando y Bravo era la verdadera herejía, no la Popular, ni la Teología de la Liberación:

La prédica de Jesús en favor de los pobres, ni la entiende ni la practica Monseñor Obando y Bravo. Desde el triunfo mismo de la Revolución en Nicaragua, se alió con los sectores más reaccionarios, con los antiguos socios de Somoza, a los que el sandinismo, magnánimamente, les permitió seguir viviendo y operando en Nicaragua.

Mucha sangre, mucho dolor, muchos huérfanos y viudas le dejó y deja esta banda de asesinos al pueblo nicaragüense, pueblo católico, como para que ahora le soporte al máximo dirigente de la Iglesia, Monseñor Obando y Bravo, que recurra a cualquier tipo de medios para proteger a los curas contrarrevolucionarios ${ }^{53}$.

Desde el Eco Católico, la Iglesia Popular fue vista no solo como un mecanismo de adoctrinamiento y control, sino también como una desobediencia clara e indiscutible a la autoridad del Papa y su representante en Nicaragua, Monseñor Obando y Bravo. Y es que el tipo de Iglesia que defendían tanto el Eco como La Nación era la que se desempeñaba como madre y maestra ${ }^{54}$, una institución que, al ser la representante de Dios en la Tierra, contaba con la autoridad moral de juzgar y tratar de orientar a los gobernantes mediante consejos y amonestaciones; una Iglesia que se posiciona más allá del Estado y toda actividad política, pero que debe estar vigilante de él y guiarlo, apelando al sentimiento cristiano de los gobernantes.

Un tipo de Iglesia que se identificara con el ordenamiento político de Occidente, una sacralización de la democracia como sistema casi perfecto y sin fallos, y acorde al proyecto político e ideológico de los sectores dominantes, donde la democracia (sin adjetivos, a pesar de ser una democracia de corte liberal) ocupaba el lugar absoluto e indiscutible para el correcto funcionamiento de la sociedad (condenando a las otras opciones, en este caso el comunismo como fallos o aberraciones) ${ }^{55}$ y por supuesto, con fuertes sentimientos anti comunistas. Estaba sumamente identificada con los programas de corte asistencialista que desde la década de 1950 los gobiernos latinoamericanos se encargaron de poner en práctica como medidas paliativas ante la creciente conflictividad social $^{56}$.

En la sección editorial del Eco, los ataques y la deslegitimación de la Iglesia Popular y la Teología de la Liberación caracterizaron el discurso, y se enfatizaba la importancia del respeto a la autoridad de las jerarquías eclesiásticas, verdaderos representantes de Cristo en la tierra. Para Eco, el gran problema de la Iglesia Popular era que venía a representar un cisma y a corromper la unidad que permitía el correcto y debido funcionamiento de la Institución, más aún si esa brecha se debía a motivos políticos (someterla a estos motivos). El 15 de agosto de 1982, en un editorial se publicaba lo siguiente:

Al pueblo fiel de Nicaragua y también para que lo entiendan los comandantes, el Papa es muy claro en establecer que la Iglesia Popular de la que se habla en Nicaragua ni es Popular, ni es Iglesia.

53. “La verdadera herejía,” Libertad, 13/19-7-1984.

54. Leonardo BofF, Iglesia: carisma y poder. Ensayos de eclesiología militante, Santander, Editorial SAL TERRAE, 1992, pp. 17 y 19.

55. Jorge RoviRA, Costa Rica en los años 80, San José, Porvenir, 1987, p. 139; Miguel PiCADO, La Iglesia costarricense entre el pueblo y el Estado (de 1949 a nuestros días), San José, Alma Mater, p. 47.

56. BofF, Iglesia, p. 18. 
Es claro que a muchos les suena bien manipular la Iglesia o la fe de los pueblos para propio provecho económico y político. La verdadera Iglesia no es así, es independiente y no claudica, su único Señor es el Señor. Dios de las naciones.

Se habla mucho de una Iglesia Popular en Nicaragua. Ojalá que no llegue el día en que se hable de Tomás Borge o alguno de los 9 comandantes como Jefe Supremo de esta Iglesia ${ }^{57}$.

Lo anterior era complementado y ampliado por otro editorial, pero esta vez publicado el 29 de julio de 1984, esta vez tocando el tema de los sacerdotes en el poder y cómo esto desafiaba la autoridad de Monseñor Obando y Bravo:

cuando el gobierno de Nicaragua otorga esos nombramientos sin el permiso de los Obispos y cuando en igual forma lo aceptan los sacerdotes, el acto en cuestión, lejos de probar que en Nicaragua no hay persecución religiosa, lo que prueba hasta la saciedad es que el gobierno nicaragüense irrespeta impúdicamente la autoridad y jurisdicción de la Iglesia sobre sus sacerdotes ${ }^{58}$.

Mientras que, en la sección “Cartas al Eco”, Héctor Pastora, presidente del Comité Ecuménico Pro Defensa Religión y Culto en Nicaragua (CEDRENIC), el 7 de agosto de 1983, se refería a los sandinistas como un "gobierno ateo, marxista-leninista [que] ha cumplido la escalada antirreligiosa de acuerdo a los lineamientos del comunismo internacional" 59 .

En La Nación, el discurso que se mantuvo fue catalogar a la Teología de la Liberación como teología de la opresión, siempre resaltando la manipulación y el adoctrinamiento como sus principales objetivos. Así lo reconocía un editorial, que denunciaba el uso erróneo y mal intencionado del concepto de liberación que promulgaba esa corriente teológica:

en efecto, el marxismo entró solapadamente en la Iglesia, con los conceptos prestados de afuera [...] liberación sí, del mal y la injusticIa. Pero esa meta no suele identificarse con los programas y la acción de movimientos destructivos y creadores de sistemas peores de opresión ${ }^{60}$.

Alberto Ordoñez, escritor y periodista nicaragüense radicado en Costa Rica, en "Foro", del 14 de julio de 1984, alegaba que

los esquizofrénicos comandantes tratan de erigir en Nicaragua una Iglesia Popular marxista leninista en contraposición de la Iglesia Católica Apostólica y Ecuménica, a la cual pertenece el credo ancestral del infortunado pueblo nicaragüense. Y esa demoníaca empresa ha lanzado a los corifeos del totalitarismo a ejecutar monstruosidades ${ }^{61}$.

\section{El punto de quiebre: la visita de Juan Pablo II a Centroamérica}

Finalmente, la visita de Juan Pablo II a Nicaragua (y al resto de Centroamérica) en marzo de 1983, fue el evento que mejor evidenció el grado de polarización que se vivía en Nicaragua durante la década de 1980. La visita del Papa generó grandes expectativas, era la primera vez que la principal autoridad eclesiástica del mundo católico venía a

57. “A confesión de parte”, Eco Católico, 15-8-1982, p. 2.

58. "Reacción de arzobispo de San José frente a las declaraciones de Ortega”, Eco Católico, 29-7-1984, p. 2.

59. Héctor Pastora, “Planes contra Obando y Bravo”, Eco Católico, 7-8-1983, p. 15.

60. “La teología de la opresión”, La Nación, 3-9-1984, p. 14A.

61. “La cruzada de Cruz por Nicaragua”, La Nación, 14-7-1984, p. 16A. 
Centroamérica; en Nicaragua, la visita planteó una serie de escenarios para los grupos en conflicto. Es importante mencionar que, junto con Ronald Reagan, Juan Pablo II fue uno de los personajes más importantes en la lucha contra la URSS (un líder tanto religioso como político) y que participó activamente en la estrategia internacional para disolver el bloque soviético, esfuerzos que fueron trascendentales para que, en su natal Polonia, el sindicato Solidaridad desafiara a la Unión Soviética y alcanzara el poder en $1988^{62}$.

El FSLN vio en la visita la oportunidad de ganar legitimidad internacional y que el Papa se solidarizara, no precisamente con la causa sandinista (el proyecto revolucionario), pero sí con su derecho a la libre autodeterminación y denunciara la política agresiva de la administración Reagan. Mientras, la Iglesia encabezada por Obando y Bravo, contaba (y así sería) con que el Papa hiciera un llamado a la unidad y al respeto a la autoridad de los obispos (castigando a los sacerdotes con puestos en el Gobierno), atacara a la Iglesia Popular y, más importante aún, diera un voto de apoyo al papel de la Iglesia como institución opositora al Frente. Desde su llegada a Nicaragua, el ambiente era tenso; el Papa, como lo señaló Sergio Ramírez, venía a confrontar a los sandinistas $^{63}$. La situación llegó al clímax cuando, durante la homilía del 4 marzo en la plaza 19 de julio ${ }^{64}$, el mensaje del Papa fue interrumpido por una multitud que gritaba y demandaba un mensaje de paz del pontífice, a lo que Juan Pablo II respondió con un llamado al silencio, y la plaza 19 de julio, pasó a escenificar la polarización religiosa e ideológica de Nicaragua.

Las repercusiones mediáticas de tal hecho no se hicieron esperar, y en Costa Rica la prensa escrita aprovechó lo sucedido para atacar o defender a los sandinistas. La Nación y el Eco se encargaron de presentarlo como un desagravio, una falta de respeto a la persona del Papa, y además se señalaba cómo los sandinistas, mediante el uso de las ventajas que tenían (control del Ejército, de los medios de comunicación, del sistema de transportes y las organizaciones de masas), pretendían politizar la visita, negando al pueblo de Nicaragua la oportunidad de que expresara su amor, pero también su dolor al sucesor de Pedro.

Así lo hacía un editorial, publicado el 13 de marzo de 1983 en Eco, en el cual se denunciaba cómo los simpatizantes sandinistas no solo fueron privilegiados, sino también, contaron con la facilidad de poder interrumpir al Papa con arengas y consignas políticas.

Como pasa en todo país comunista, cuando hay un evento nacional, los tiquetes se dan a los partidarios y miembros del partido. Así es en Nicaragua. Para la ida de Juan II, los primeros puestos se dieron a los seguidores de la fiera política que detenta el poder.

El locutor era un sandinista por supuesto y todo el sistema de radio y televisión estaba controlado por ellos. Esa es la razón por la cual dos voces de “turba” pudieron gritar a través del micrófono sin que fueran molestadas, ni siquiera en el momento de la

62. Josep Fontana, Por el bien del imperio. Una historia del mundo desde 1945, Barcelona, Pasado y Presente, 2013, pp. 612 y 685.

63. Sergio RAmíREZ, Adiós muchachos. Una memoria de la revolución sandinista, México, Aguilar, 1999. p. 195.

64. En esta homilía, Juan Pablo II hizo un fuerte llamado a respetar la unidad de Iglesia y al respeto indiscutible e innegable a la autoridad de los obispos (ver Héctor FERLLinI, Miguel DíAz y Oscar CASTILLO, (comps.), Un viaje histórico. El Papa en una región de conflicto, San José, Uruk Editores, 1983, pp. 9094). 
consagración del pan y el vino. Las consignas gritadas fueron consignas políticas, así como el discurso de bienvenida dicho por Ortega en el aeropuerto ${ }^{65}$.

La Nación, junto con las denuncias de politización de la visita, fue enfática en aseverar que quienes ofendieron al Papa no fueron los nicaragüenses (el pueblo católico oprimido), sino los sandinistas, seres ajenos y ateos, además de irrespetuosos. Dos editoriales, uno del 30 de diciembre de 1982 y otro del 6 de marzo de 1983, lo impugnaban.

El primero de ellos, sobre la politización, expresaba:

Cuando su santidad Juan Pablo II visite Managua en marzo del año entrante se dará uno de los fenómenos más interesantes desde el punto de vista político. Es evidentemente un huésped no grato a la junta sandinista y al gobierno revolucionario, que solo lo recibirá, según el protocolo de los nueve comandantes, si fuera como jefe de Estado y no como jefe de una Iglesia. Pero por otro lado es, con clarísima evidencia, un huésped muy grato al pueblo nicaragüense, la mayoría del cual es católico devoto y practicante.

El que Su Santidad haya resuelto visitar Nicaragua, sin esperar el beneplácito, menos aún la invitación de las autoridades antisandinistas, es una forma de respaldo a la Iglesia que en estos momentos tiene una profunda significación para las fuerzas de la oposición ${ }^{66}$.

Por supuesto, desde La Nación y el Eco no se veía como politización que el Papa apoyara a la Iglesia Oficial, ni mucho menos que Obando y Bravo fuera presentado como un líder de la oposición anti sandinista; los elementos políticos eran suavizados o presentados en términos religiosos o espirituales. Para ambos periódicos, el apoyo no era político, representaba la manera de actuar de los cristianos ante la injusticia, actuar que se justificaba dentro de la larga tradición de resistencia de la Iglesia. No se reconocía que la cúpula eclesiástica nicaragüense era sumamente politizada, tanto en su apoyo a la contrarrevolución como en los esfuerzos deslegitimadores (la descalificación moral) del régimen y su trabajo a nivel interno e internacional articulando sus acciones con el trabajo conjunto con los líderes de la oposición, principalmente aquellos vinculados con el Consejo Superior de la Empresa Privada (COSEP) y la Coordinadora Democrática Nacional ${ }^{67}$.

Al hacerlo así, se trataba de crear un clima de opinión desfavorable hacia los sandinistas, donde la víctima era el Papa, y por extensión todo el mundo católico. Al victimizarlo, el discurso buscaba generar no solo empatía (apelar a lo emocional) tanto con la figura de Juan Pablo II y la Iglesia y el pueblo nicaragüense; también se encargaba de presentar a los sandinistas como el enemigo, no solo de la democracia, ahora también de la religión y de Dios. Esa lucha entre el bien y el mal, la dicotomía/polarización de Nicaragua en dos bandos, se puede notar en el segundo editorial de La Nación:

\footnotetext{
Sabíamos que el régimen sandinista hacía preparativos para manipular políticamente la visita de Juan Pablo II a Nicaragua. Sabíamos de las trabas impuestas a decenas de miles de creyentes deseosos de asistir al encuentro del Santo Padre. Sabíamos también que habría pancartas, turbas amaestradas y amenazadas. Pero nunca pudimos imaginar que la consigna de los nueve dictadorzuelos sería convertir un acto de fe cristiana, de recogimiento y meditación en un espectáculo circense.

Así fue, sin embargo, y con ello no solo se ha agraviado a la figura del Vicario de Cristo, sino también a todos los creyentes católicos y, principalmente, al pueblo nicaragüense, amante de Dios y de la Iglesia. Más aún, ese acto vergonzoso, vil,
}

65. “Para tonto no hay que estudiar”, Eco Católico, 13-3-1983, p. 2.

66. “La no visita del Papa”, La Nación, 30-12-1982, p. 14A.

67. Cáceres y otros, Iglesia, política y profecía, p. 188. 
incivilizado, es la mejor prueba para los que aún comulgan con ruedas de molino, de cuál es la verdadera naturaleza del régimen que los nueve fidelitos de bolsillo quieren imponer a un pueblo que los rechaza ${ }^{68}$.

Denunciar que el Papa se dejó mal informar por parte de Obando y Bravo y la CEN fue algo que el discurso de Libertad y Universidad resaltaron, además de lamentar la distancia y el desconocimiento entre Juan Pablo II y la realidad que vivían los pueblos latinoamericanos, caracterizada por un pasado violento y represivo, el terrorismo de Estado y las desigualdades económicas ${ }^{69}$. Ese desconocimiento permitió que el mensaje del Papa se redujera a una simplificación ideológica, a la lucha entre comunismo y democracia, dejando de lado todas las contradicciones sociales, políticas y económicas que justificaron y orientaron el derrocamiento de Somoza y la Revolución Sandinista.

Virginia Grutter publicaba, en el número 577 de Universidad lo decepcionante y frustrante que fue la visita de Juan Pablo II para el pueblo nicaragüense, pueblo que, como lo venía haciendo el discurso de quienes escribían en el semanario, sufría, pero no claudicaba en su apoyo a la Revolución:

El Papa fue mal informado respecto a la actitud y necesidades del pueblo nicaragüense

[...] El pueblo esperaba palabras de paz y consuelo y el Papa entabló un diálogo de sordos.

Los nicas querían una oración por sus mártires, los que siguen cayendo en la lucha por defender a Nicaragua de las bandas somocistas. Las madres, levantando las fotos de sus hijos caídos, gritaban "solo las Marías”, aludiendo así a que eran las madres de los nuevos crucificados, y el Papa no oía.

El Papa, mal informado, continuaba defendiendo una unidad que, como queda dicho, nadie amenaza ${ }^{70}$.

El artículo de Grutter, también como lo hacía La Nación y el Eco, dirigió su discurso a tocar los sentimientos y tratar de generar empatía hacia las madres de los soldados caídos, y con ello se buscaba establecer una relación entre ese ideal de deber y sacrificio (que dentro de la retórica sandinista eran elementos claves en el proyecto revolucionario) con el Gobierno del Frente. De igual manera, el uso de la figura de la madre y sus deseo por una plegaria para sus hijos era un recurso discursivo importante para legitimar al régimen y a quienes luchaban por él. Para Lorraine Bayard, en momentos de fuerte conflictividad y violencia como el que atravesaba Nicaragua durante la década de 1980, la imagen de la madre y sus quejas fueron utilizadas en favor de una causa (defensa del régimen) y señalar a los causantes de esas quejas (la Contra) como la fuente de todo $\mathrm{mal}^{71}$.

En Libertad, fue William Venegas, en un artículo de la semana del 29 de abril al 5 de mayo de 1983, quien se refirió a la visita de Juan Pablo II en términos muy similares a los expresados por Grutter, acusando los intentos por

\begin{abstract}
Aislar al Pontífice católico de un sector determinado de la Iglesia, del progresista comprometido en la lucha popular por la justicia social [... de] la iglesia siempre joven, progresista, popular [...] junto al pueblo en su lucha por mejores condiciones de vida, por construir una sociedad liberada por siempre del imperialismo. Es la Iglesia Popular que
\end{abstract}

68. “Agravio a un pueblo,” La Nación, 6-3-1983, p. 14A.

69. Cáceres, y otros, Iglesia, política y profecía, p. 182.

70. “El Papa y los nicaragüenses”, Universidad, n. 577, 4-1983, p. 4.

71 Lorraine Bayard, "Mobilizing mothers for war: cross-national framing strategies in Nicaragua's contra war”, Gender and society, 18, n. 6 (2004), p. 716. 
los sectores tradicionales y burgueses clasifican como un “escándalo” en sus actuaciones $^{72}$.

\section{Conclusión}

A lo largo del presente artículo se pudo constatar cómo el discurso mediático de la prensa costarricense se encargó de construir una imagen e idea de la Iglesia católica nicaragüense que, en un contexto de Guerra Fría y de crisis centroamericana, terminó siendo un campo de batalla en donde se enfrentaban concepciones sobre el papel de la institución y cómo ésta se vinculaba con el tipo de democracia que cada periódico defendía desde su posición ideológica. Así, en cada una de las publicaciones consultadas, tanto en editoriales como en artículos de opinión, lo político se vinculó con lo religioso con el fin de explicar, o al menos acercarse, a lo que estaba sucediendo en Nicaragua luego del triunfo de la Revolución Sandinista.

Cada uno de los periódicos partió de una interpretación de la realidad en donde, rayando muchas veces en lo propagandístico, se presentaban elementos y discursos favorables y desfavorables sobre los Sandinistas, los miembros de la Iglesia católica o aquellos sacerdotes que ocupaban puestos dentro del Gobierno revolucionario. Fue así cómo las representaciones de la Iglesia, tanto la oficial como la popular, partían de una visualización del momento que atravesaba Nicaragua como una batalla, ya fuera entre el bien y el mal, entre la resistencia y la instrumentalización (La Nación y Eco Católico) o entre ponerse del lado de los más necesitados y enfrentarse al imperio (Universidad y Libertad).

Desde la figura de Monseñor Obando y Bravo, pasando por qué era la Iglesia popular, hasta cómo recibir a Juan Pablo II, todos fueron temas de discusión y análisis, y al hacerlo crear climas de opinión que justificaran y legitimaran, ya fuera el ataque o el apoyo al proyecto revolucionario sandinista. Fue así como la religión pasó a ser un elemento importante en la manera en que la Guerra Fría fue vivida en Centroamérica. La experiencia nicaragüense y cómo esta era percibida desde Costa Rica ayudan a comprender mejor el papel jugado por quienes desde las páginas de un diario o un semanario determinaban la finalidad de la Iglesia en una región en conflicto. Sus reflexiones partían también de un interés por definir qué tipo de democracia debía orientar al país recientemente se había liberado de una larga experiencia dictatorial.

De tal manera, en cada uno de los discursos y representaciones se van a encontrar una serie de conceptos claves que al fin de cuentas son aquellos que orientan la forma en cómo se percibía a una buena iglesia y a un buen cristiano: obediencia, compromiso, anticomunismo, justicia social. Cada uno de ellos, dentro del discurso, terminó siendo instrumentalizado sin importar si fuera desde un periódico con una tendencia izquierdista u otro con una clara inclinación a la derecha.

Así, como se planteaba al inicio de este artículo, a través de la prensa se buscó socializar y poner en discusión (y consumo) una serie de valores, ideas y visiones de mundo en función de la posición de cada uno de los periódicos consultados. Cabe destacar que cada uno de los discursos consultados sobre la Iglesia partía de lo expuesto por actores que en el medio del periodismo escrito costarricense contaban con una importante cuota

72. “La otra visita”, Libertad, 5-5-1983, p. 4. 


\section{ASTORGA}

de prestigio, no solo personal (para el caso de columnistas como Enrique Benavides o intelectuales como Virginia Grutter, entre otros), sino también institucional, resultado éste del medio en el cual escribían y para el cual algunos trabajan.

Aunque este trabajo se encargó de analizar qué se decía en la prensa sobre la Iglesia, tanto la tradicional como la popular, se puede llegar a plantear, a modo de reflexión (y esperando futuras investigaciones sobre el tema) que la Revolución Popular Sandinista, el triunfo del Frente y la puesta en marcha del proyecto político revolucionario provocaron un conflicto en el seno de la Iglesia, entre aquellos sacerdotes que se posicionaron del lado de Obando y Bravo y otros cercanos a los sandinistas. Ante tal posicionamiento, fue la Iglesia tradicional la que mejor supo sacar provecho de la religiosidad de los y las nicaragüenses, debido a la larga tradición y al peso de la Iglesia como Institución. No es que la Iglesia Popular no fuera exitosa, sino que contaba con una menor exposición en términos temporales con la población. Queda por delante un trabajo que se encargue de estudiar tal situación.

Finalmente, el propósito de este trabajo es abrir una mayor discusión en torno al papel que han jugado, y siguen jugando, instituciones claves en la región centroamericana. Y es que, durante la más reciente crisis en Nicaragua, la Iglesia católica se posicionó en el centro de la arena política al presentarse como mediadora. Queda por lo tanto camino por recorrer e investigar. 